\title{
Expansão urbana e dinâmica imobiliária: comparando as estratégias fundiárias dos agentes imobiliários em cidades médias
}

\section{Urban Expansion and Real Estate Dynamics: Comparing Real Estate Agent Land Strategies in medium-sized cities}

\section{Bruno Leonardo Silva Barcella ${ }^{1}$} Everaldo Santos Melazzo ${ }^{2}$

\begin{abstract}
Resumo
$\mathrm{O}$ artigo analisa as recentes expansões territoriais urbanas de duas cidades médias (Ribeirão Preto/SP e São Carlos/SP), argumentando sobre a estreita relação entre interesses e estratégias de determinados agentes fundiários e imobiliários e a seletiva direção, ritmo, escopo e porte das citadas expansões do tecido urbano. Para tanto, os dados de transações fundiárias (compra e venda) entre os anos de 1995 e 2015, seus preços e informações a respeito da produção de espaços residenciais fechados e seus principais agentes são analisados. Adotase, como pano de fundo para o debate, o desvendamento da busca permanente pela reprodução ampliada do capital mediante a lógica que situa a cidade como "lócus" das estratégias de acumulação que articulam no plano econômico a transformação de rendas da terra em lucros de incorporação e no plano espacial a seletividade e diferenciação do espaços da moradia.

Palavras-chave: Produção do espaço urbano. Mercado de terras urbanas. Cidades médias. Ribeirão Preto. São Carlos.
\end{abstract}

Palavras-chave: Produção do espaço urbano. Mercado imobiliário. Cidades médias. Ribeirão Preto. São Carlos.

\begin{abstract}
This article analyzes the recent urban territorial expansion in two medium-sized Brazilian cities (Ribeirão Preto/SP and São Carlos/SP) and discusses the close relationship between the interests and strategies of specific real estate and land agents and the selective direction, rhythm, scope, and magnitude of the cities' expansion. To this end, data on land transactions (purchase and sale) between 1995 and 2015, are mapped for both cities, showing the prices, information on the production of gated communities, and the main agents involved. Their permanent quest to amplify the reproduction of capital is the backdrop for the debate, through a logic that places the city as the "locus" of the accumulation strategies. This is articulated in the economic dimension by the transformation of land income into incorporated profits and spatially by the differentiated, exclusive housing.
\end{abstract}

Keywords: Urban space production. Real estate market. Medium cities. Ribeirão Preto. São Carlos.

\footnotetext{
${ }^{1}$ Universidade Estadual Paulista, Presidente Prudente, São Paulo, Brasil. blbarcella@gmail.com
}

2 Universidade Estadual Paulista, Presidente Prudente, São Paulo, Brasil. e.s.melazzo@gmail.com 


\section{Introdução}

O presente artigo constrói uma abordagem que busca avançar na compreensão dos processos da produção do espaço urbano em cidades médias no período recente. Para isso, o artigo se debruça sobre dois exemplos concretos, analisando as cidades de Ribeirão Preto e São Carlos, ambas no Estado de São Paulo. A construção analítica enfatiza a relação de mão dupla entre expansão territorial urbana e os agentes imobiliários ganha centralidade, com vista a uma aproximação da "essência" do funcionamento dos mercados fundiários, de maneira a compreender seus papéis na produção estruturação e reestruturação das cidades.

Busca-se colocar em primeiro plano o desvendamento da lógica de atuação de determinados agentes imobiliários que podem ser considerados como estruturantes (LOGAN; MOLOTCH, 1987; FIX, 2007), que representam uma lógica de valorização intrínseca à reprodução do capital incorporador (SMOLKA, 1987; ABRAMO, 1989; MELAZZO, 1993) e que possuem um papel fundamental no processo de estruturação dos espaços das cidades (SMOLKA, 1987; MELAZZO, 1993), processo este cada vez mais conduzido por tais agentes, que tomam as cidades como o "lócus" de sua valorização através da produção e captura de rendas fundiárias.

Nesse sentido, o artigo é iniciado com uma breve descrição dos processos recentes de expansão territorial urbana de cada cidade aqui considerada, processos esses que tiveram sua origem, direcionamento e planejamento diretamente associados aos interesses estratégicos de determinados agentes imobiliários que resultam no que é denominado como "vetores de expansão e valorização imobiliária", assim como definido em Barcella (2018). Para a realização desta descrição são retomados os processos de expansão do perímetro urbano a partir do final dos anos 1980 e início dos anos 1990 até o presente momento, dando destaque a determinadas áreas e bairros de cada cidade, articulados a uma certa tipologia de habitação, os segmentos socioeconômicos a que se destinam, dados os preçosd a terra nelas praticados e a resultante seletividade e diferenciação em relação à cidade.

Por fim, nas considerações finais busca-se, de maneira sintética, elencar as principais conclusões resultantes do debate, compreendendo a produção do espaço urbano como resultante de lógicas econômicas e espaciais que ganham força no período recente, impondo às duas cidades analisadas alterações substanciais em seus processis de estruturação/reestruturação. Indagase, ao final, sobre se tais características poderiam ou não ser observadas em outras cidades do mesmo estrato da rede urbana.

\section{Agentes imobiliários, estratégias fundiárias e produção do espaço: a constituição dos "vetores de expansão e valorização imobiliária" nas cidades de Ribeirão Preto/SP e São Carlos/SP}

Os processos recentes de expansão territorial urbana nas cidades de Ribeirão Preto e São Carlos indicam alterações profundas nas formas e conteúdos do processo de produção do espaço urbano. Ao identificar os grupos econômicos que a 
comandam, suas intencionalidades e estratégias, econômicas e espaciais, busca-se destacar suas lógicas de atuação que conformam e resultam no que é aqui denominado como "vetores de expansão e valorização imobiliária”.

A terminologia "vetor" foi escolhida pois observa-se em tais processos um sentido e direção clara, determinados estrategicamente. É a partir da construção e incorporação de determinados empreendimentos que é possível observar a expansão do perímetro urbano das cidades, com conteúdos diferenciados e estrategicamente pensados em determinadas direções.

As estratégias de atuação destes agentes resultam em uma "valorização" seletiva e intencional de algumas áreas da cidade. Tal "valorização" (que não é espontânea e sim produzida), além de possuir uma direção clara em cada cidade analisada. articula a incorporação de grandes extensões de terras ao tecido urbano e lhe conferem um conteúdo diferenciado e seletivo quando comparados a outras áreas e bairros.

Enfim, recorre-se à ideia do vetor para sublinhar que esses recentes processos de expansão do tecido urbano possuem sua concepção e origem diretamente associados aos interesses de determinados agentes imobiliários, que buscam conduzir seus ganhos convertidos em forma de rendas fundiárias com a implantação de empreendimentos imobiliários que vão além somente da produção de habitação, buscando sinergias com outros usos do solo, atuando de forma integrada para modificar áreas inteiras, que geram externalidades e conferem diferenças substanciais àqueles espaços em relação à cidade como um todo. São identificados nessas novas áreas urbanas mudanças profundas nos padrões de uso e ocupação do solo urbano em relação a estrutura da cidade que se apresentava até esse momento, observa-se nessas novas áreas novas tipologias que buscam uma combinação clara entre o residencial e o comercial voltados para públicos de segmentos econômicos restritos, o que garante a manutenção e potencialização da elevação de preços.

Nesse sentido, tais empreendimentos acabam por condicionar o padrão futuro de uso e ocupação de áreas que estão nucleadas por eles. Trata-se, portanto, da expansão dos negócios imobiliários, com a criação de novas áreas que já nascem "valorizadas", possuindo alto preço do metro quadrado ofertado.

O recorte temporal adotado destaca os processos de expansão dos tecidos urbanos que tiveram relação direta com a formação dos vetores identificados e que podem ser datados, ainda que de forma incipiente, a partir da década de 1980, como será argumentado a seguir.

Figueira (2013), relata que a cidade de Ribeirão Preto, já na citada década, vivenciou um momento ímpar em sua conjuntura urbana com o aumento da renda per capita, dos fluxos de capital e emprego, principalmente nos setores comerciais e de serviços urbanos, devendo ser considerada ainda uma extensa e dinâmica inserção nos circuitos produtivos ligados ao açucar e álcool, uma das bases da economia local e regional. De acordo com a autora, os desdobramentos daquela conjuntura de crescimento econômico frente ao conjunto da economia nacional foram sentidos na própria estrutura da cidade, com o processo de deslocamento dos segmentos populacionais de 
renda elevada em direção ao eixo sul-sudoeste, se opondo espacialmente aos conjuntos habitacionais de interesse social que se instalavam no norte e noroeste da cidade (FIGUEIRA, 2013).

Portanto, indentifica-se, no decorrer dos anos 1980, o início do processo de "valorização" do eixo ou vetor sul da cidade o que, no decorrer das décadas seguintes, se revelou como definidor de uma mudança estruturante e profunda, fruto de uma articulação que envolveu os principais agentes imobiliários locais, o poder público municipal e alguns proprietários de terras.

Tal articulação trouxe resultados expressivos na dinâmica imobiliária local nos anos 2000, com uma intensificação dos negócios imobiliários, articulando verticalização, espaços residenciais fechados horizontais e "shopping centers", tanto na esfera da produção, quanto na esfera do consumo imobiliário (BARCELLA, 2018; ABREU, 2019).

Em São Carlos, cidade que articula a densa e dinâmica rede urbana em que se insere e bastante conhecida pela forte presença de instituições de ensino superior, pode-se identificar o início e intensificação de processo semelhante ao sumariamente descrito para Ribeirão Preto.

$\mathrm{Na}$ Figura 1 estão delimitados os polígonos, numerados sequencialmente pela ordem temporal de sua produção/implantação, que representam a localização e o tamanho das áreas que foram planejadas e que vem sendo paulatinamente produzidos pelo GDU-RP. Foge ao escopo deste trabalho o detalhamente de cada uma (BARCELLA, 2018; ZAMBONI, 2018; ABREU, 2019), mas é possível observar sua concentração espacial ao sul e suas dimensões no contexto da cidade como um todo, sendo a primeira o já citado Jardim Santa Ângela, onde se encontra a Av. Prof. João Fiúza.

Porém, dadas os sempre presentes condicionantes locais que alteram e diferenciam tais processos, apresenta temporalidade distinta daquela anterior, com menor escopo do ponto de vista quantitativo, mas não menos marcante para cidade, com o "aumento da aprovação e lançamento de espaços residenciais fechados voltados, sobretudo, aos segmentos de médio a alto poder aquisitivo" (DAL POZZO, 2011, p. 63), principalmente a partir de meados dos ano de 1990.

É possível afirmar, assim, que o processo de expansão dos negócios imobiliários, no que se refere a uma atuação mais sistemática de certos agentes econômicos relevantes, ainda foi de certa forma "tímido" em um primeiro momento, aprofundando-se posteriormente (BARCELLA, 2018).

Desta maneira, a expansão territorial urbana de São Carlos, diretamente ligada à constituição de um certo vetor de valorização ocorreu mais intensamente a partir dos anos de 2000 em direção a noroeste da malha urbana e posteriormente em direção ao norte, sendo caracterizada pela implantação de espaços residenciais fechados (DAL POZZO, 2011).

Em síntese, observa-se, em ambas as cidades processos recentes, mas não sincrônicos, semelhantes, mas não iguais, de expansões territoriais urbanas com vínculos diretos nos interesses de determinados agentes imobiliários capazes de impactar e alterar de forma direta a estrutura das cidades (BARCELLA, 2018). 
Figura 1. Ribeirão Preto. Áreas indutoras do vetor de expansão e valorização imobiliária.

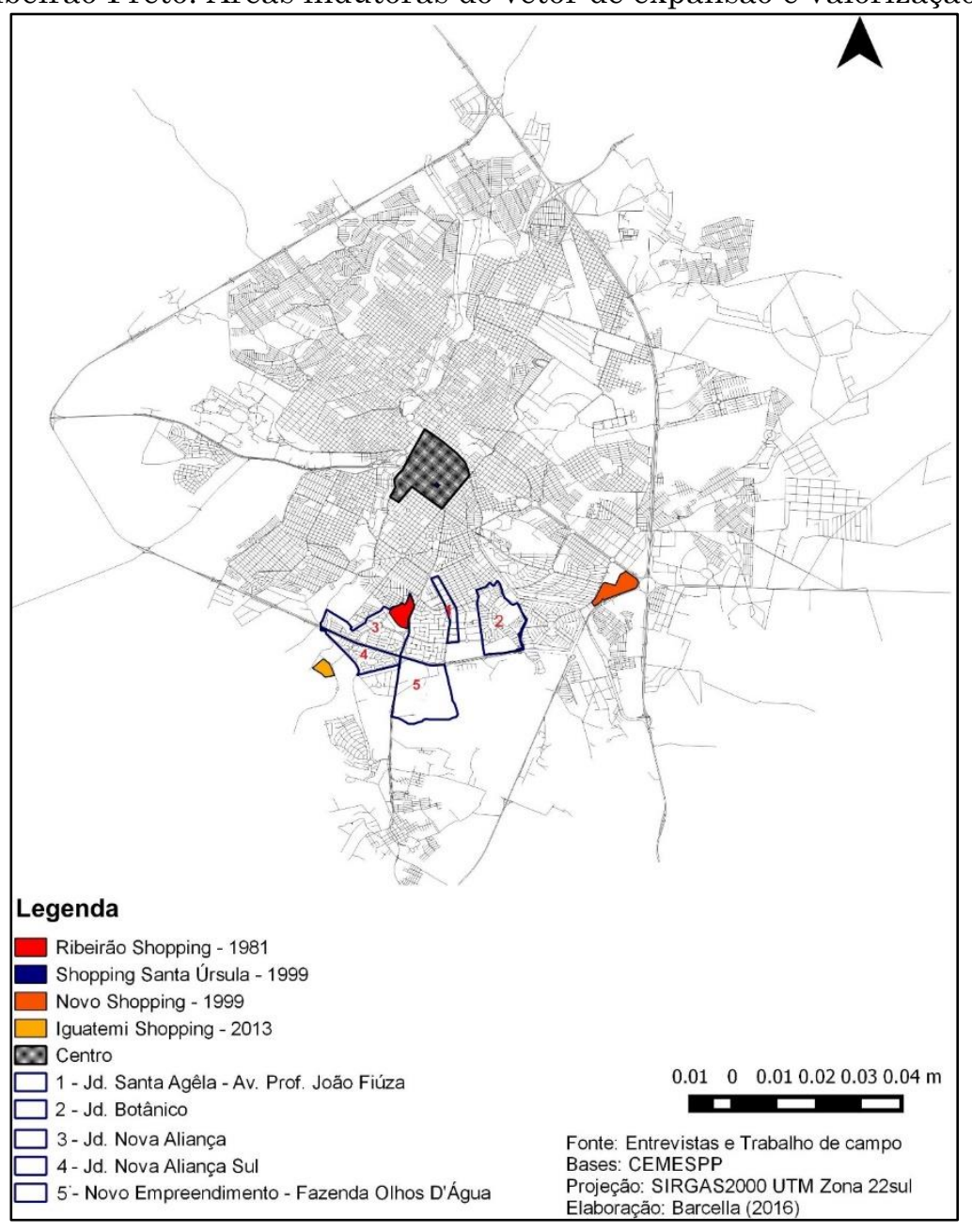

Fonte: Barcella (2018)

Em relação a Ribeirão Preto, o ponto de inflexão encontra-se associado ao aparecimento de uma lógica de atuação de determinados agentes imobiliários, tendo como base de suas estratégias as intervenções urbanas planejadas pelo Grupo de Desenvolvimento Urbano (GDU), em parceria com algumas empresas imobiliárias locais, poder público municipal e proprietários de terra.

O GDU é formado pelas empresas imobiliárias Habiarte Barc, Copema, Pereira Alvim e Stéfani Nogueira, todas de capital originalmente de Ribeirão Preto e já atuantes no mercado imobiliário local e regional, constituindo uma nova empresa de consultoria de planejamento urbano, criada para prestar serviços especializados em planejamento urbano para o poder público municipal. Passa a tomar para si a responsabilidade pelo planejamento de várias áreas na cidade a partir dos anos 1990, articulando-se diretamente com outras empresas imobiliárias locais.

Para a reconstituição do processo de planejamento urbano que é chamado a atenção pós-1990 e análise da relação de determinados agentes com tais processos, utiliza-se entrevistas realizadas com profissionais ligados a algumas destas empresas. É importante destacar que todas as entrevistas utilizadas foram gravadas com a 
devida ciência dos entrevistados e autorização dos mesmo para a utilização do material. O banco de informações obtidas nas entrevistas conta com um número expressivo de entrevistas autorizadas com diferentes agentes, tais como: gerentes e diretores de imobiliárias, corretores imobiliários, diretores executivos de importantes incorporadoras, representantes do poder público do setor de planejamento, empresários imobiliários e até mesmo professores universitários que residem e pesquisam o tema em tais cidades, as entrevistas foram realizadas baseadas em um roteiro de questões "chave" para subsidiar as análises. É importante ressaltar que tais entrevistas foram realizadas no âmbito do Projeto de pesquisa temático financiado pela FAPESP "Lógicas econômicas e práticas espaciais contemporâneas: cidades médias e consumo".

A partir transcrição de todas as entrevistas constrói-se um banco de informações obtidas que possibilitem análises mais complexas no que diz respeito às estratégias de determinados agentes imobiliários que são considerados centrais para explicar e entender a trajetória da dinâmica imobiliária nas cidades em questão.

Com a análise detalhada das entrevistas, observa-se uma estreita relação entre elas, o Grupo de Desenvolvimento Urbano (GDU-RP) e o poder público municipal. De acordo com o Entrevistado I (Diretor Executivo da Habiarte Barc) o grupo foi criado no início dos anos 1990, com o intuito de atuar junto ao poder público municipal no "desenvolvimento urbano" da cidade de Ribeirão Preto. A escolha minuciosa de novas áreas da cidade e o planejamento estratégico de implementação de determinados empreendimentos teve início com a concepção e lançamento do Jardim Santa Ângela no ano de 1996, situado ao sul da área central da cidade. Nas palavras no Entrevistado,

"Ribeirão Preto, assim como em qualquer outra cidade do interior de São Paulo, o mercado de alto padrão estava no centro da cidade, famílias tradicionais e público de alto poder aquisitivo. Na década de 1990 foi concebido um projeto que foi na verdade uma intervenção urbana que foi chamada de Jardim Santa Ângela aqui na zona sul de Ribeirão Preto" (ENTREVISTADO I, 2015).

Segundo ainda o mesmo Entrevistado, o Jardim Santa Ângela foi concebido como um bairro "âncora" que buscava introduzir uma nova dinâmica de incorporação na direção sul da cidade de Ribeirão Preto, por meio da incorporação de terras e seu parcelamento destinadas a diversas tipologias, usos e densidades, desde que voltados a segmentos socioeconômicos capazes de pagar preços fundiários e imobiliários acima daqueles praticados em todas as demais áraes da cidade. Insistindo na ideia da "operação urbana" como ação intencional deste grupo de empresas, o Enrevistado acrescenta que

"Então o Grupo de Desenvolvimento Urbano que é a sociedade do presidente da empresa( Fundador e Presidente da Habiarte Barc e um dos fundadores da GDU-RP.) com outras empresas, fundaram o grupo e viabilizaram a operação urbana. Eles lotearam essa região (sul) criando lotes para prédios residenciais altos, prédios comerciais e loteamentos para casas, condomínios de casas de alto padrão, e esses lotes foram planejados, projetados para atender ao público de alto padrão. Adotaram parâmetros urbanísticos que não havia em Ribeirão Preto[...] esta operação, esse projeto, inclusive ganhou o Prêmio Master Imobiliário em 2007" (ENTREVISTADO I, 2015). 
Tratou-se, portanto, de uma "operação urbana" em seu sentido amplo, da produção de uma grande área da cidade e diante de tamanhas transformações, as áreas localizadas ao sul da cidade paulatinamente ganharam importância e se tornaram as principais áreas de interesse dos agentes imobiliários que buscavam atender ao público de maior poder aquisitivo da cidade, a partir da construção de prédios residenciais de alto padrão, com tamanhos e conteúdos diferenciados daqueles existentes no centro da cidade, na medida em que "uma vez lançado, o mercado de alto padrão saiu do centro e migrou para a zona sul"(Entrevistado I).

No centro desta "operação urbana" e como elemento crucial para sua viabilização encontravam-se as paulatinas aquisições de banco de terrenos por parte das citadas empresas. O controle antecipado da propriedade tornou-se o mecanismo chave no controle da produção imobiliária posterior.

De acordo com o Entrevistado II (Entrevista cedida pelo Gerente Comercial da COPEMA, gravação e utilização autorizada pelo entrevistado), um dos grandes diferenciais destas empresas imobiliárias locais, que até os dias atuais tem sua atuação direcionada ao sul, é justamente os bancos de terras que foram previamente adquiridos, o que conferiu a elas o domínio sobre os títulos de propriedade, conferindo-lhes vantagens na concorrência com outras empresas.

"Um diferencial em relação ao que você está perguntando é o seguinte: as construtoras de Ribeirão já vinham com um bom estoque de terras, áreas muito bem localizadas, quer dizer, quando chegaram as empresas de fora, não totalmente, mas as áreas estrategicamente já estavam, das incorporadoras de Ribeirão Preto e isso foi um diferencial" (ENTREVISTADO II, COPEMA, 2015).

Revela-se a importância conferida pelas empresas à formação de seus bancos de terras, condição econômica e espacial, que assume papel central na concorrência intercapitalistas, em seus processos de planejamento estratégico de expansão dos negócios, nos lançamentos imobiliários e no controle antecipado da produção da cidade.

A partir do planejamento ancorado na aquisição prévia e no consequente domínio de vastos bancos de terras em determinadas áreas de interesse dos citados agentes, que acabaram por formar os setores localizados ao sul da cidade de Ribeirão Preto, houve a possibilidade de que estas empresas imobiliárias de origem local pudessem, através do GDU-RP e o aval/atuação do poder público municipal, produzir estrategicamente a expansão territorial urbana, resultando no vetor de expansão e valorização imobiliária em direção ao sul da cidade.

Em síntese, a coalização de interesses entre as citadas empresas imobiliárias locais, organizadas a partir do GDU-RP, desempenharam um papel central no que se refere à coordenação dos investimentos no ambiente construído nas últimas décadas na cidade de Ribeirão Preto. Diante disso, tais agentes foram e são peças fundamentais no processo de estruturação e reestruturação da cidade, sendo possível argumentar sobre sua crucial importância para o entendimento das lógicas espaciais e econômicas destes capitais. Não deixa de ser relevantes, ainda, 
a articulação direta com o poder público municipal, debate este que, entretanto, foge ao escopo desta artigo, mas que pode ser compreendido em Barcella (2018); Zamboni (2018) e Abreu (2019).

Em São Carlos, o processo de expansão urbana mais recente, que resultou na produção de espaços diferenciados em determinadas periferias, pode ser datado a partir dos anos de 1990, tendo como um de seus principais marcos a implantação do Parque Faber I, aprovado no ano de 1990, localizado no noroeste da malha urbana (DAL POZZO, 2011).

Dal Pozzo (2011) relata que esse processo se inicia a partir do interesse de determinados empresários de setores econômicos que não os do ramo imobiliário que, em determinado momento, passaram a investir seus capitais na produção do ambiente construído com a concepção de projetos urbanísticos em uma determinada periferia da cidade.

Observa-se, portanto, o início da expansão territorial urbana direcionada ao setor noroeste da cidade, diretamente associada a interesses de uma determinada empresa que passa a ter seus ganhos vinculados à produção do ambiente construído da cidade. É nesse momento que é identificado o primeiro, mas ainda incipiente indicio de um processo recente de expansão do perímetro urbano.

A Faber Castell, tradicional indústria de materiais para escrita, desenho e pintura, instalada na cidade de São Carlos há mais de 70 anos, era proprietária de extensas áreas localizadas no extremo norte [setor noroeste] da cidade, onde realizava plantio de pinus (...) a Sobloco, no início de 1980, propôs à Faber Castell, uma associação, com o objetivo de realizar um plano de desenvolvimento urbano que fosse capaz de absorver, a longo prazo e de forma organizada, o crescimento comercial, residencial e de serviços de São Carlos. Desta forma, nasceu em projeto intitulado PLANO URBANÍSTICO DO PARQUE FABER (DAL POZZO, 2011, p. 121).

Destaca-se, portanto, a parceria realizada entre uma empresa do setor industrial de materiais de escrita, desenho e pintura (Faber Castell) e uma construtora originária da própria cidade de São Carlos, a Sobloco Construtora.

A partir da incorporação das terras da primeira, foi criado um planejamento "que incluiu empreendimentos residenciais fechados, de grande porte e de alto padrão construtivo. O planejamento buscou, usando as mesmas palavras presentes no material de divulgação do projeto, uma forma "organizada de absorver a longo prazo o crescimento comercial, residencial e de serviços de São Carlos" (DAL POZZO, 2011, p. 121), mas sobre o qual acrescentamos, de maneira diferenciada e direcionada exclusivamente aos segmentos socioeconômicos de rendas elevadas.

Porém, se os empreendimentos do Parque Faber encontra-se o início do processo de criação de um vetor de expansão e valorização imobiliária, sua consolidação irá ocorrer apenas no decorrer da década de 2000, principalmente a partir do início da atuação sistemática de um novo agente, cuja origem não é local, o Grupo Encalso Damha que se torna o grande responsável pela consolidação do vetor em destaque. É a partir dos anos de 2000, portanto, que se observa uma intensificação dos negócios imobiliários e um processo paulatino e constante de expansão do tecido urbano estrategicamente pensado, a partir de então, na direção norte e noroeste (DAL POZZO, 2011; 


\section{BARCELLA, 2018).}

No setor norte, foram implantados doze espaços residenciais fechados, sendo três deles de pequeno porte e oito de médio a grande porte. Mais especificamente, na Figura 2, destacamos os empreendimentos indutores do vetor de expansão e valorização imobiliária. São eles os quatro espaços residenciais fechados, quais sejam, o Parque Residencial Damha I, II e III e o Village Damha São Carlos I e II, todos contíguos ao Parque Eco-esportivo Damha, abrangendo 1.200 hectares e que congrega um conjunto de áreas voltadas para o esporte e o lazer (incluindo campo de golf e centro hípico), além do complexo empresarial Parque Ecotecnológico Damha (DAL POZZO, 2011).

Destaca-se, a partir da análise da Figura 2 a atuação do Grupo Encalso Damha, criado no ano de 1964 na cidade de Presidente Prudente/SP, atuando, nos dias atuais, na produção de obras de Engenharia Civil, em Agronegócios, na Concessão de Rodovias, Gestão de Shopping Center, Concessão de Energia e Empreendimentos Imobiliários de acordo com informações obtidas em seu sítio eletrônico.

O Grupo Encalso Damha adquire no ano de 1995 a grande gleba de terras na qual passa a implantar seus empreendimentos a partir da segunda metade dos anos 2000 assumindo protagonismo no processo de expansão do perímetro urbano em direção ao norte da cidade de São Carlos (BIZZIO, 2015). Assim como os empreendimentos do Parque Faber, mas de maneira mais marcante frente ao conjunto da cidade, os empreendimentos do Grupo Encalso Damha promoveram uma mudança intensa dos padrões de uso e ocupação do solo naquela periferia da cidade.

Os citados empreendimentos passam não apenas a determinar novo eixo diferenciado de expansão e valorização. Passa também a funcionar como importantes indutores dos padrões futuros de uso e ocupação do solo urbano nas áreas nucleadas por eles, consolidando o vetor pelos seguintes motivos: I) o Parque Faber I consiste no primeiro grande espaço residencial fechado de grande porte da cidade, implantado em área não central, integrando o uso residencial, comercial e de serviço (DAL POZZO, 2011) e induzindo a implantação de um segundo empreendimento da mesma construtora (Parque Faber II) e o Residencial Swiss Park, lado a lado e contínuos ao Shopping Iguatemi, além de outros espaços residenciais fechados implantados em áreas próximas no decorrer da década de 2000. II) Já no que se refere ao setor norte da cidade, ressalta-se o papel central dos empreendimentos do complexo Damha como forte indutor do "vetor de expansão e valorização imobiliária”. Segundo Dal Pozzo (2011, p.126) o Grupo Encalso caracterizou-se como um dos principais agentes que contribuíram para "induzir a formação de um novo eixo de expansão e de segmentação do espaço urbano no Setor Norte". 
Figura 2. São Carlos. Áreas indutoras do vetor de expansão e valorização imobiliária. 2016

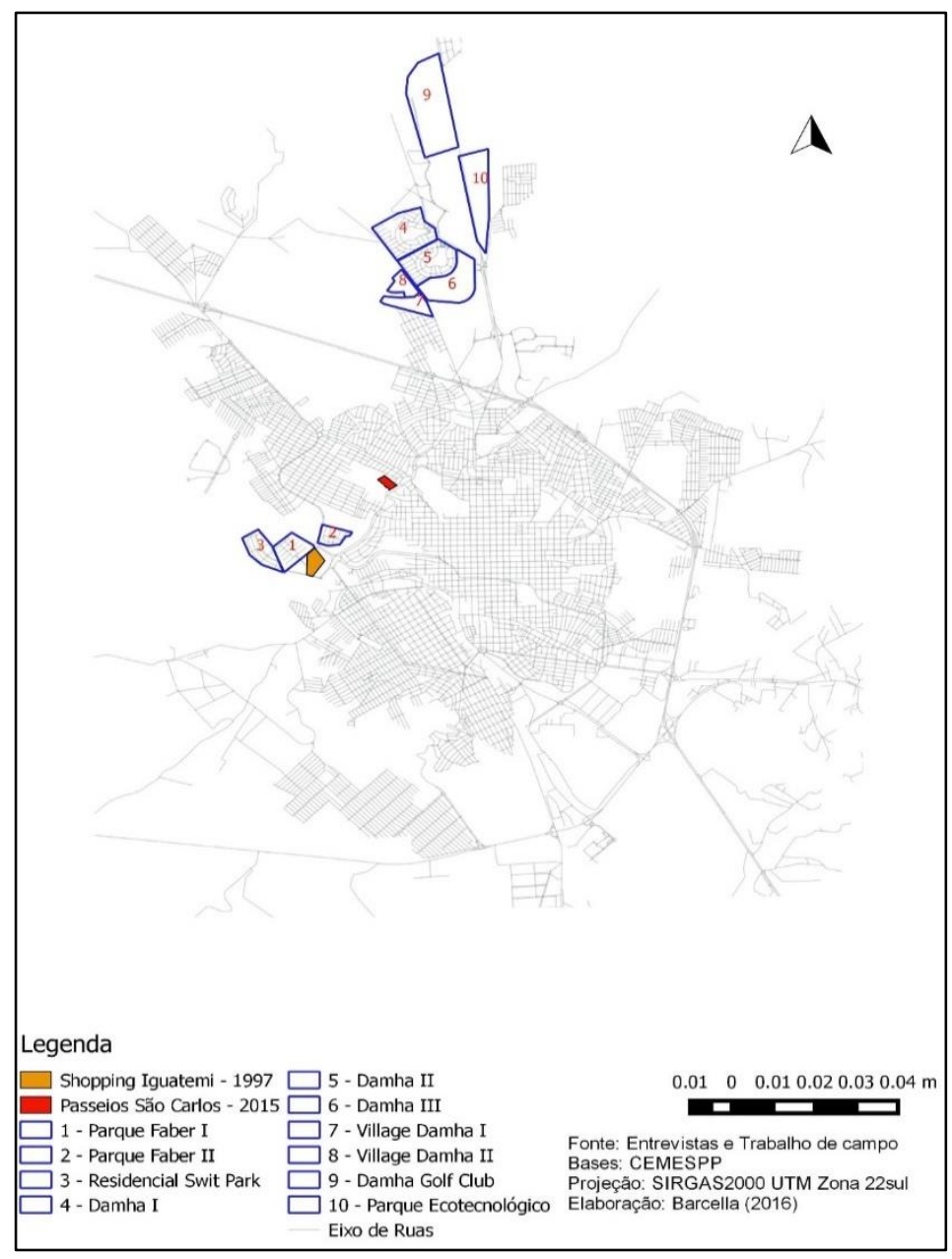

Fonte: Barcella (2018)

Nesse sentido, observa-se que a expansão territorial urbana mais recente da cidade de São Carlos, em direção ao norte e noroeste da cidade, não foi um processo espontâneo nem neutro, e sim um processo pensado a partir das estratégias e planejamento de determinados agentes, diferenciando seus produtos e desencadeando suas ações a partir do controle sobre a propriedade fundiária de grandes extensões de terra com bastante anterioridade.

Com estratégias bastante similares às empresas analisadas no caso anterior, em São Carlos também aparecem com nitidez as realções diretas e próximas com o poder público local
(BIZZIO, 2015; BARCELLA, 2018).

\section{O capital incorporador e os "vetores de expansão e valorização imobiliária": as lógicas que orientaram a reprodução do capital mediante a produção do ambiente construído}

No item anterior foram identificados os agentes e as resultantes espaciais de sua estratégica e seletiva atuação, o que conduziu à expansão dos perímetros urbanos das cidades nas últimas décadas, o que deve ser interpretado pela busca permanente dos mecanismos que lhes garantam a 
apropriação de rendas fundiárias urbanas cada vez maiores, base de seus ganhos imobiliários em contextos urbanos de grande disponibilidade de terras para serem incorporadas ao usos também urbanos.

O modus operandi está diretamente associado às características de atuação dos agentes que representam o capital incorporador, sendo ele o capital que coordena as bases da produção das rendas fundiárias urbanas, buscando a partir da modificação do status da terra (a partir da incorporação) e do ambiente construído a maior extração possível de rendas (SMOLKA, 1987).

Nesse sentido, o capital incorporador passa a conceber espaços diferenciados em ambas cidades. Tais espaços possuem uma grande relevância para o entendimento da produção do espaço urbano de ambas as cidades, sendo possível destacar tal relevância em dois principais aspectos:

I) O tamanho/extensão territorial das incorporações e modificação dos espaços, na cidade de Ribeirão Preto a soma do tamanho dos empreendimentos que foram destacados ultrapassa $1.632 .900 \mathrm{~m}^{2}$, segundo os agentes imobiliários entrevistados, visto que essa é a soma do tamanho dos empreendimentos, Jardim Botânico, Nova Aliança e Nova Aliança Sul. Já na cidade de São Carlos o Grupo Encalso Damha produziu mais de $1.479 .974 \mathrm{~m}^{2}$ de lotes urbanizados em espaços residenciais fechado, de acordo com as informações disponibilizadas na página oficial da empresa. Ou seja, do ponto de vista quantitativo, são observadas mudanças grandes dos espaços da cidade sob orientação desse capital, bem como a incorporação de grandes áreas ao espaço urbano das cidades, aglutinando quantidades substanciais de terrenos urbanos sob seu controle/propriedade;

II) Do ponto de vista qualitativo, levando em consideração os novos conteúdos por eles produzidos, resultando em diferenciações espaciais e novos vetores de expansão dos negócios imobiliários, tendo um papel crucial no padrão de uso e ocupação futuro de vastas áreas da cidade.

Nesse sentido, é possível avançar a hipótese de que tal conjunto de mudanças, orquestrado por esse capital, tem papel determinante na estruturação e reestruturação dos espaços das cidades.

Tal interpretação permite observar a atuação dos agentes que representam o capital incorporador como central na condução e concepção dos vetores de expansão e valorização imobiliária a partir de uma lógica que visa não somente a captação de rendas fundiárias urbanas com a transformação de terra rural em terra urbana ou na mudança de conteúdo do ambiente construído, mas também a criação de tais rendas a partir dos movimentos de antecipação e coordenação da organização do ambiente construído (SMOLKA, 1987; ABRAMO, 1989) que claramente está em curso nas cidades em destaque.

A partir desta interpretação, identifica-se ainda que os agentes imobiliários já destacados podem ser entendidos como agentes estruturantes (LOGAN; MOLOTCH, 1987; FIX, 2007), na medida em que

[...] não apenas procura prever o futuro para 
tomar suas decisões, como também intervém para altera-lo, modificando as condições que estruturam o mercado. A estratégia é criar rendas diferenciais, por meio da influência na arena de tomada de decisões que trazem vantagens a uma região em relação a outra, como a realização de obras públicas, a oferta de subsídios, as alterações no zoneamento, a elaboração de planos etc. (FIX, 2007, p.25).

Assim, a atenção nesse momento recai sobre a análise da relação entre o mercado fundiário urbano e a atuação do capital incorporador que, segundo Smolka (1987), é o capital responsável por comandar o processo de criação e captura de rendas fundiárias, é o capital essencial para o funcionamento do mercado fundiário.

Melazzo (2015) chama a atenção para a necessidade de uma apreensão cada vez maior do conjunto de mudanças em curso nos processos de produção das cidades brasileiras exigindo assim a análise, cada vez mais apurada das estratégias dos agentes imobiliários (e os capitais que eles representam) que hoje produzem a cidade, pois as estratégias de atuação desses agentes são cada vez mais seletivas e complexas e produzem cada vez mais espaços diferenciados.

A partir deste alerta destaca-se elementos que corroboram com as estratégias e lógicas de atuação destes agentes, uma vez que se encontram diretamente ligadas à formação dos vetores de expansão e valorização imobiliária, a partir do controle de extensos estoques de terras nas cidades e a construção de relações próximas ao poder público local.

O controle de extensos bancos de terrenos e a proximidade com o poder público conferiu a estes capitais, nos casos em destaque, possibilidades de articular estratégias que lhes garantiram e garantem a produção e captação de rendas fundiárias urbanas ao longo dos anos, resultando em espaços cada vez mais diferenciados nas duas cidades, o que acaba por alterar significativamente suas estruturas.

Segundo Smolka (1987, pp.41), o capital incorporador manipula as bases das rendas fundiárias, assumindo papel central e potencialmente estruturante na produção e planejamento do ambiente construído. Abramo (1989) confere a ele a função de coordenação dos demais capitais que fazem parte do circuito imobiliário urbano, que é composto por diferentes agentes que representam diferentes capitais e que fazem parte do processo produtivo imobiliário.

A partir da lógica de atuação que envolve todo o circuito imobiliário urbano, entende-se a atuação do capital incorporador como aquele que se valoriza e se expande ao assumir o controle do processo pelo qual rendas fundiárias são criadas e apropriadas. Portanto, o capital incorporador é caracterizado como aquela fração do capital que possui sua atuação a partir do controle sobre as bases em que a renda fundiária é alterada (SMOLKA, 1987).

Tal articulação, que garante a maior captação possível de rendas fundiárias urbanas, é evidenciada nas estratégias de formação e consolidação dos vetores de expansão e valorização imobiliária como o eixos de áreas/bairros que apresentam os maiores preços do metro quadrado ofertado em ambas as cidades.

É possível identificar essa tendência de consolidação de vetores de expansão e valorização imobiliária ao longo da série histórica de 1995 à 2015 (Figuras 3 e 4). 
A análise da série histórica representada pelo conjunto de mapas de preços evidencia um claro movimento de "valorização" de algumas localizações "menos" centrais a partir do aumento expressivo do preço do $\mathrm{m}^{2}$ de tais áreas e até mesmo a partir da inserção delas dentro da dinâmica imobiliária local, conformando eixos específicos em direção a uma determinada periferia, em ambas as cidades.

Os dados representados nas Figuras 3 e 4 expõem os preços do $\mathrm{m}^{2}$ anunciados de terrenos urbanos em ambas as cidades, no recorte temporal de 1995 a 2015. O procedimento metodológico utilizado para coletar e sistematizar os dados apresentados diz respeito à coleta de preços imobiliários ofertados junto aos anuncios de jornais de ambas as cidades. Esse mesmo procedimento metodológico para constituição de uma base de dados de preços imobiliários já é amplamente utilizada por um conjunto de pesquisadores que estudam a dinâmica imobiliária em cidades médias. Tal procedimento encontra-se devidamente detalhado em Melazzo (1993), Abreu e Amorim (2014), Abreu (2014) e Barcella (2017; 2018), dentre outros.

Os preços da terra, tomados comparativamente em diferentes áreas/bairros sinalizam as diferenças que moldam as possibilidades de acesso e consumo de cada parcela do solo em cada localização na exata medida em que os preços do solo expressam sua renda potencial. 
Figura 3. Ribeirão Preto. Os preços médios ofertados de terrenos urbano. 1995 - 2015

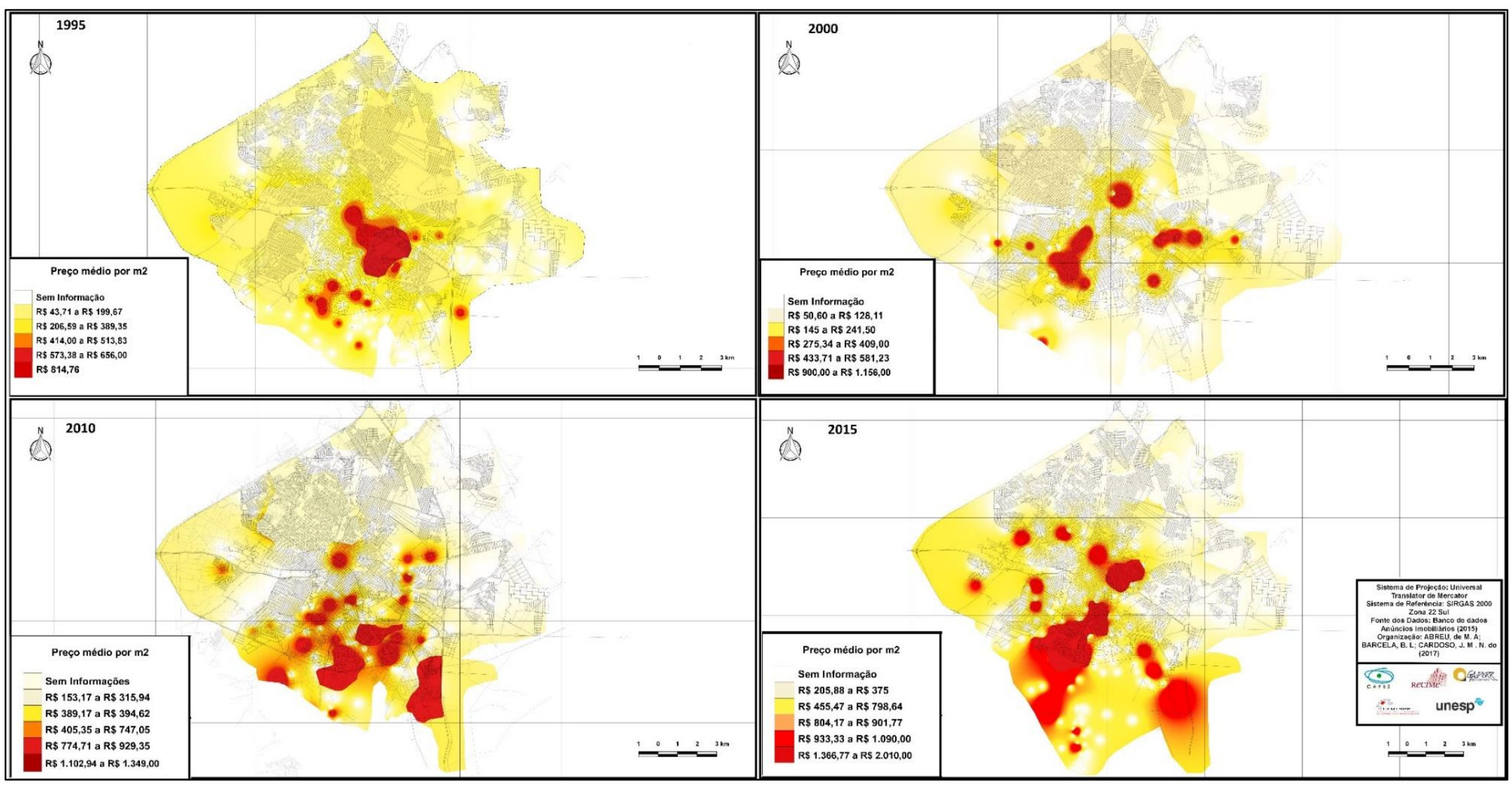

Fonte: Barcella (2018) 
Figura 4. São Carlos. Os preços médios ofertados de terrenos urbano. 1995 - 2015

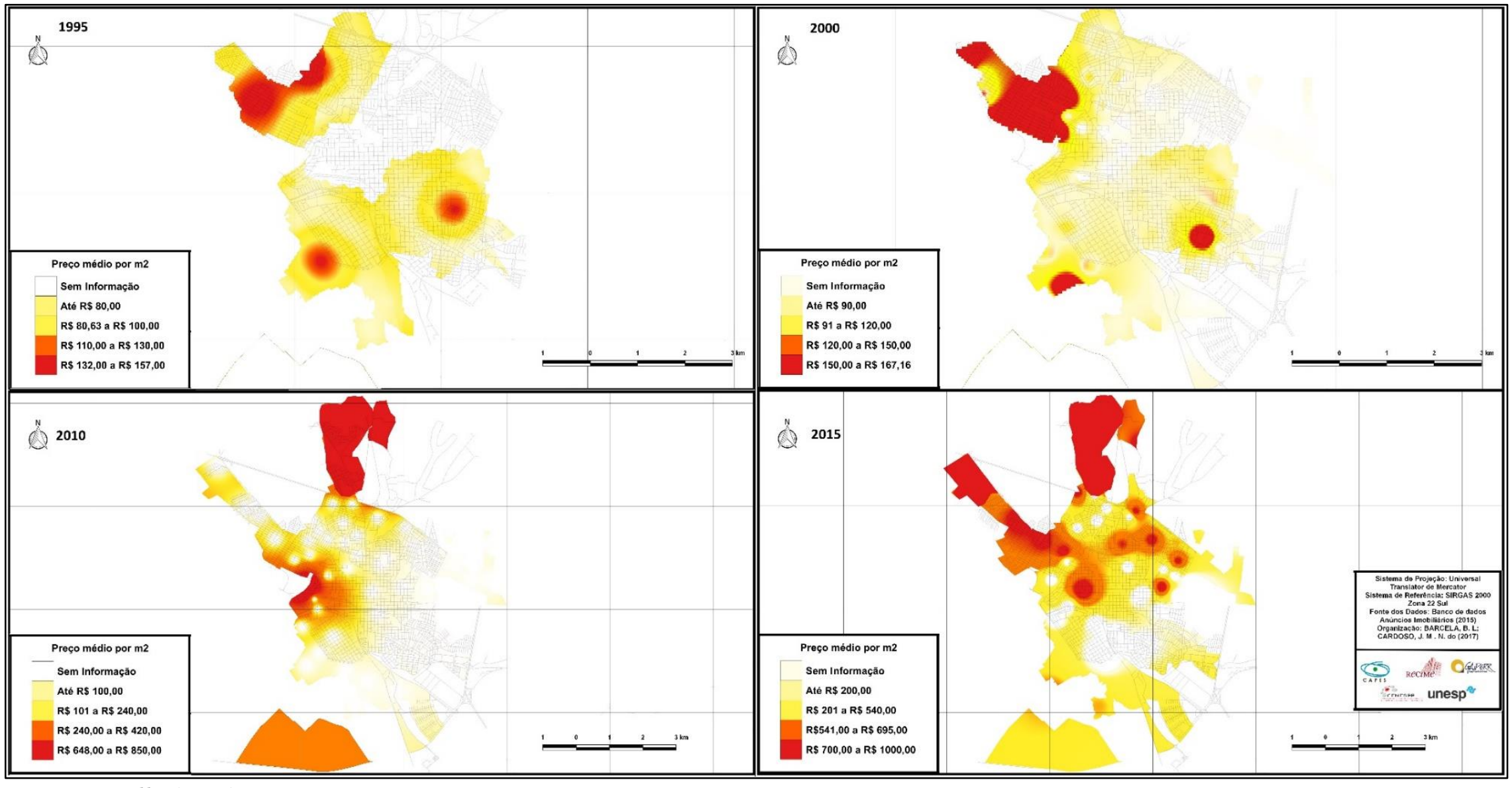

Fonte: Barcella (2018) 
É neste sentido que o Gráfico 1 apresenta a comparação entre os preços médios da terra urbana ofertada nos bairros que compõe os vetores de expansão e valorização imobiliária e os preços médios ofertados no restante da cidade, nos anos de anos de 2010 e 2015 de ambas as cidades.

O Gráfico 1, assim, permite verificar nas duas cidades o quão diferentes são os preços do metro quadrado em bairros situados nos vetores de expansão e valorização e fora deles, apresentando distâncias que se materializam concretamente nas localizações, tipologias e qualidades distintas da produção e do consumo do ambiente construído urbano. Nos vetores, ainda, os preços mantém-se sistematicamente superiores aos preços médios da cidade como um todo.

Além disto, observa-se ainda a ampliação das diferenças entre o ano de 2010 e 2015. Sobem os preços médios da cidade em seu conjunto, sobem os preços do metro quadrado dos terrenos fora dos eixos, mas sobretudo sobem os preços exigidos para o acesso a estes vetores diferenciados em cada cidade. Seletivamente, portanto, vão se consolidando como espaços exclusivos.

Gráfico 1. Ribeirão Preto e São Carlos. Preços médios da terra urbana ofertados nos vetores de expansão e valorização imobiliária e no restante da cidade. 2010 - 2015

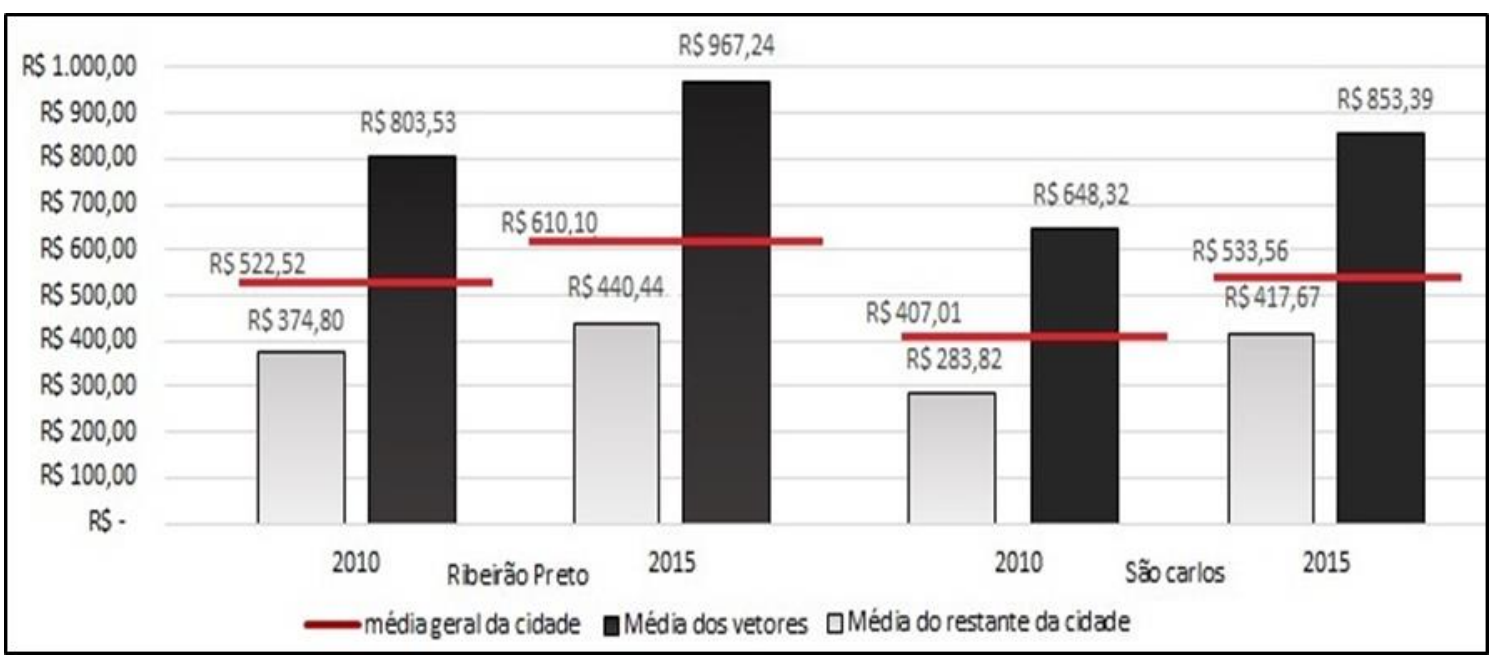

Fonte: Barcella (2018).

\section{Considerações finais}

Ao analisar os exemplos empíricos apresentados de Ribeirão Preto e São Carlos e identificando e reconhecendo as lógicas de atuação dos agentes que tem seus ganhos diretamente ligados aos empreendimentos imobiliários que induziram o surgimento e consolidação dos vetores de expansão e valorização imobiliária, destacam-se dois grandes agentes, que são emblemáticos dessa lógica: em Ribeirão Preto, o GDU-RP, representando a articulação das principais empresas imobiliárias da cidade e na cidade de São Carlos, o Grupo Encalso Damha, grupo de capital externo à cidade.

Considera-se o capital incorporador como aquele que atua sobre desenvolvimento do espaço urbano, organizando os investimentos privados no 
ambiente construído, buscando a partir disto sua continua e ampliada reprodução (SMOLKA, 1987). observa-se a pertinência da utilização desse conceito como um dos caminhos a explicar a atuação destas empresas nas cidades aqui estudadas.

As estratégias dos citados agentes foram analisadas no texto como indutoras de um movimento de incorporação de novas áreas urbanas que nascem no âmbito do interesse do mercado imobiliário, sendo denominadas como vetores de expansão e valorização imobiliária.

Enfim, a partir da discussão teórica construída, é possível levantar quatro características principais da lógica de atuação dos agentes que representam o capital incorporador em ambas as cidades - I) a busca por vasto controle de terras das cidades, para assim melhor conduzir suas estratégias de rentabilidade a partir da extração de rendas fundiárias (SMOLKA, 1987), possível nestas cidades pela ampla disponibilidade de terras a serem incorporadas; II) a busca por coordenar todo o circuito imobiliário urbano (ABRAMO, 1989), sendo portanto a fração do capital que conduz as estratégias de transformação do ambiente construído (SMOLKA, 1987; ABRAMO, 1989). A partir da análise da atuação do GDU-RP em Ribeirão Preto e do Grupo Encalso Damha em São Carlos observa-se uma função clara de tais agentes na coordenação de estratégias que conduzem os investimentos privados e a produção do ambiente construído em ambas as cidades; III) a proximidade com o setor público (SMOLKA, 1987; ABRAMO, 1989), com o objetivo de alcançarem melhores condições para a reprodução do capital, a partir de marcos legais e institucionais que possibilitem a execução de suas estratégias de produção no ambiente construído, sendo que tal característica ficou evidente a partir das entrevistas realizadas com os próprios agentes e com representantes do setor público e, por fim, IV) a elevação dos preços da terra urbana, produzida por estes capitais em suas respectivas áreas de atuação, em relação ao conjunto das cidade, indicam o sucesso de suas estratégias de controle e expansão das próprias rendas fundiárias urbanas, base da rentabilidade do setor para os processos de acumulação capitalista dos agentes envolvidos.

Os processos aqui analisados ajudam a explicar o movimento de ampliação das desigualdades socioespaciais nestas cidades que parecem se reproduzir com intensidade em várias outras do mesmo estrato da rede urbana brasileira. Portanto, espera-se que os argumentos expostos e as evidências empíricas apresentadas possam contribuir para o necessário debate a respeito dos desafios, limites e potencialidades da produção de cidades menos excludentes e mais democráticas.

\section{Referências}

ABRAMO, P. A dinâmica imobiliária. Elementos para o entendimento da espacialidadeurbana. Cadernos IPPUR, Rio de Janeiro, Ano III, $\mathrm{N}^{\circ}$ especial, 1989.

ABREU, M. A. de. Diferenciando o espaço e produzindo cidades: lógicas e agentes da produção do espaço urbano em Ribeirão Preto/SP e Londrina/PR. 2014. 171f. Dissertação (Mestrado em Geografia), Faculdade de Ciências e Tecnologia, Universidade Estadual Paulista "Júlio de Mesquista Filho". Presidente Prudente, 2014. ABREU, M. A. de; AMORIM, W. V. O estudo do 
mercado imobiliário em cidades médias: procedimentos para coleta e sistematização dos dados. GeoUERJ, Rio de Janeiro, v. 21, p. 297 323 , 2014. http://dx.doi.org/10.12957/geouerj.2014.10403

ABREU, M. A. de. Produção imobiliária e os espaços da financeirização: entre o abstrato da riqueza financeira e o concreto da cidade produzida. 232 f. Tese (Doutorado em Geografia) - Faculdade de Ciências e Tecnologia, Universidade Estadual Paulista "Júlio de Mesquista Filho". Presidente Prudente, 2019.

BARCELLA, B. L. S. O mercado fundiário em Ribeirão Preto/SP: processos e agentes, preços e localizações. Caminhos de Geografia, v. 18, n. 62, p.161-173, 21 jun. 2017. EDUFU Editora da Universidade Federal de Uberlandia, 2017. http://dx.doi.org/10.14393/rcg186213

BARCELLA, B. L. S. A dinâmica dos agentes imobiliários e suas estratégias fundiárias em cidades médias: da reprodução do capital à reprodução das desigualdades socioespaciais. 2018. 217 f. Dissertação (Mestrado) Universidade Estadual Paulista, Faculdade de Ciências e Tecnologia, FCT/UNESP Câmpus de Presidente Prudente, 2018.

BIZZIO, M. R. Condomínios residenciais fechados: a urbanização do Grupo Encalso Damha em São Carlos - SP. 151 f. Dissertação (Mestardo) - Faculdade de Ciências e Letras, Universidade Estadual Paulista "Júlio de Mesquista Filho". Araraquara, 2015.

DAL POZZO, C. F. Territórios de autossegregação e de segregação imposta: fragmentação socioespacial em Marília e São Carlos. Presidente Prudente, 2011. 316 f. Dissertação (Mestrado em Geografia) Faculdade de Ciências e Tecnologia, Universidade Estadual Paulista "Júlio de Mesquista Filho". Presidente Prudente, 2011.

FIGUEIRA, T. M. B. Produção social da cidade contemporânea. Análise dos Condomínios Urbanísticos e Loteamentos Fechados de Alto
Padrão do Subsetor Sul de Ribeirão Preto / SP. 2013,198 f. Dissertação (Mestrado em Arquitetura e Urbanismo) - Instituto de Arquitetura e Urbanismo de São Carlos, Universidade de São Paulo, São Carlos, 2013.

FIX, M. São Paulo cidade global. Fundamentos financeiros de uma miragem. São Paulo: Boitempo, 2007.

LOGAN, J. R.; MOLOTCH, H. L. Urban fortunes. The political economy of place. Los Angeles: University of California Press, 1987.

MARQUES, E. De volta aos capitais para melhor entender as políticas urbanas. Revista Novos Estudos. CEBRAP. São Paulo. v. 35.02, p. 1533, 2016. http://dx.doi.org/10.25091/s01013300201600020002

MELAZZO, E. S. Mercado imobiliário, expansão territorial e transformações intraurbanas: o caso de Presidente Prudente SP. 1993. Dissertação de Mestrado. (Mestrado em Planejamento Urbano e Regional). Instituto de Pesquisa e Planejamento Urbano e Regional (IPPUR), Universidade Federal do Rio de Janeiro, 1993.

MELAZZO, E. S. Interações, combinações e sinergias: produção do espaço urbano, dinâmicas imobiliárias e o programa minha casa minha vida em cidades médias brasileiras. In: BELLET, C.; MELAZZO, E. S.; SPOSITO, M. E. B.; LLOP, J. M. (org.) Urbanização, produção e consumo em cidades médias/intermediárias. Universidade Estadual Paulista - Presidente Prudente, Edicions de la Universitat de Lleida, Presidente Prudente y Lleida, 2015.

SMOLKA, M. O capital incorporador e seus movimentos de valorização. Cadernos IPPUR/UFRJ, Rio de Janeiro, p. 41-78, ano II, n.1, jan/abr, 1987.

ZAMBONI, D. P. A territorialidade do capital: da fazenda ao condomínio, desenhando a cidade. Tese (Doutorado em Gestão e Planejamento Territorial), Unversidade Federal do ABC, 2018. 